\title{
Basilar artery aneurysm and Anderson-Fabry disease
}

\author{
D N MAISEY, AND J A COSH \\ From the Royal United Hospital, Bath
}

SUMMARY A case of basilar artery aneurysm is described. The patient had a family history of similar aneurysms and also of a rare sphingolipidosis, Anderson-Fabry disease.

Anderson-Fabry disease is a rare $\mathrm{X}$-linked disorder of sphingolipid metabolism in which there is an accumulation of ceramide trihexoside ${ }^{1}$ caused by the absence of an enzyme, ceramide trihexosidase, ${ }^{2}$ a specific $\alpha$-galactosidase. ${ }^{3}$ Wallace 4 has reviewed the widespread clinical manifestations, which include a characteristic skin rash (angiokeratoma corporis diffusum), hypertension, renal failure, and neurological manifestations. The latter consist of attacks of severe peripheral pain, strokes, dementia, and other symptoms. Hemizygous males are clinically affected much more than heterozygous females. ${ }^{5}$

There are characteristic histological changes in many organs, the most significant involving the smooth muscle of the media of small arteries. ${ }^{6}$ In the central nervous system neurovascular abnormalities are prominent though individual nerve cells are also directly affected. ${ }^{7}$ Gross dilatation of the arteries at the base of the brain may occur. ${ }^{4}$

We describe here a case of basilar artery aneurysm occurring in a woman with a well-documented family history of Anderson-Fabry disease but who showed no other diagnostic features of the disease.

\section{Case report}

A 50 year old woman presented to one of us (JAC) in 1970 with hypertension which had been first noted 20 years earlier. She had suffered from agoraphobia for many years. Her blood pressure

Address for reprint requests:Dr DN Maisey, Department of Medicine, Addenbrookes Hospital, Cambridge CB2 2QQ

Accepted 7 June 1979 was $200 / 140 \mathrm{mmHg}$ and there was a loud aortic seccnd sound and grade 2 retinopathy. No neurological abnormalities were observed. Renal function was found to be normal.

In 1973 she was admitted to another hospital with weakness, apathy, and urgency incontinence. Extensor plantar responses were noted. Skin lesions on the right wrist and left shin were thought to be neurodermatitis, and her symptoms were thought to be psychological in origin.

In 1976 she presented to the Royal United Hospital, Bath with a severe influenza A pneumonia, requiring intermittent positive pressure ventilation. After ventilation had been discontinued she had episodes of dysphagia and inhalaticn and developed an aspiration pneumonia which necessitated a further period of intermittent positive pressure ventilation. At this time her tongue was noted to be fasciculating. A detailed neurological examination revealed a euphoric affect, nystagmus to the left, intrinsic muscle wasting of the hands, mild incoordination in the upper limbs, and a right extensor plantar reflex. In retrospect there was a one-year history of memory disturbance and drowsiness. Choking had been observed before her admission to hospital.

Computerised axial tomography (Frenchay Hospital, Bristol) showed dilatation of the lateral ventricles with a lesion that impinged on the third ventricle and enhanced with meglumine iothalamate (Conray). Angiography (fig 1) showed a $70 \mathrm{~mm}$ diameter elongated basilar artery aneurysm, the remainder of the basilar artery being grossly elongated and tortuous. A carotid arteriogram was also abnormal showing elongation and tortuosity of the other major vessels. 


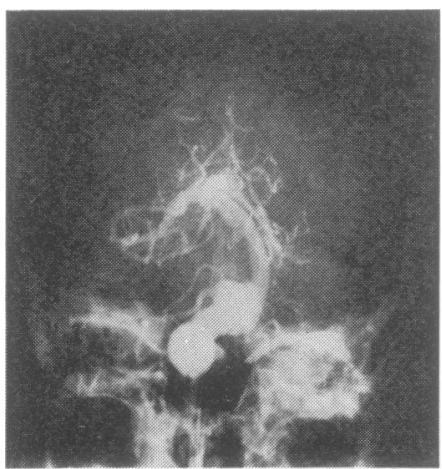

Anteroposterior view of left vertebral angiogram showing giant basilar artery aneurysm.

No surgical treatment was undertaken. Careful clinical examination of her skin and eyes failed to reveal any features characteristic of Anderson-Fabry disease. She died suddenly six months later after experiencing increasingly severe occipital headaches. No necropsy was performed.

\section{FAMILY HISTORY}

Our patient was the grand-daughter of Anderson's patient ${ }^{9}$ (Wallace, personal communication), and the family has been described in detail by Wise et al. ${ }^{8}$ Our patient's mother died aged 57 years after a six-month period of apathy and loss of memory, followed by coma for three days. Postmortem examination of her kidneys confirmed that she had Anderson-Fabry disease. There was gross fusiform dilatation of the arteries of the base of the brain, particularly the basilar, and a pontine haemorrhage. Steward and

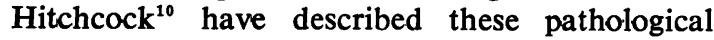
findings in detail. Wallace ${ }^{4}$ has published a photograph of the brain which shows the vessels to bear a striking resemblance to that indicated by the angiograms in our patient.

Our patient's brother died aged 50 years of nenal failure caused by Anderson-Fabry disease. $\mathrm{He}$ also had gross vertebral and basilar arterial dilatation practically identical to that of his mother (Wallace, personal communication).

\section{Discussion}

Aneurysm and elongation of the basilar artery is a recognised cause of posterior fossa symptoms and signs. These changes are usually ascribed to atherosclerosis. ${ }^{11}$ Anderson-Fabry disease has not been recognised as a potential cause. ${ }^{12} \mathrm{~A}$ familial tendency to basilar artery aneurysm has not been described.

The relationship between the arterial changes observed in our patient and Anderson-Fabry disease is open to more than one interpretation. Our patient's mother showed that women patients with Anderson-Fabry disease may not have the characteristic rash. $^{13}$ However heterozygous women can virtually always be detected by careful ophthalmological examination of the cornea. $^{14}$ Our patient had a $50 \%$ chance of inheriting the disease from her mother. ${ }^{14}$ Possibly she had the disease manifested clinically only by hypertension, presenile dementia, and abnormalities of the large cerebral arteries. The alternative explanation is that she was not a carrier of Anderson-Fabry disease but had inherited from her mother some other genetic tendency to basilar artery aneurysm formation. Several authors do not refer to large cerebral artery abnormalities as a feature of Anderson-Fabry disease. ${ }^{71617}$ Christensen Lou and Reske-Nielsen ${ }^{18}$ described slight diffuse thickening of the arteries of the circle of Willis in one case, and pronounced atherosclerotic changes in another. It may be that the occurrence of basilar artery aneurysm in the mother and brother of our patient was coincidental. Steward and Hitchcock ${ }^{10}$ did not state whether the mother's basilar aneurysm showed histological features specific to Anderson-Fabry disease. They implied that it was the result of atherosclerosis. Possibly our patient's mother and brother also had hypertension and this was the common factor resulting in the aneurysm.

The findings in this case suggest that more information on the frequency and pathogenesis of basilar artery aneurysm is required before it can be regarded as a feature of Anderson-Fabry disease. It would be interesting to determine whether there is a familial tendency to basilar artery aneurysm or whether there is a familial relationship to Anderson-Fabry disease. It should be noted that the diagnosis of Anderson-Fabry disease is frequently missed or long delayed. ${ }^{10}$

We acknowledge gratefully the help of Dr G Wakefield, Mr D Phillips, Mr J Griffiths, and Dr $\mathbf{R}$ Tan in the clinical care of this patient, and in particular Dr $\mathrm{H}$ Wallace for much helpful information.

\section{References}

1 Sweeley CC, Klionsky B. Fabry's disease: classification as a sphingolipidosis and partial characterisation of a novel glycolipid. J Biol Chem 1963; 238:3148-50. 
2 Brady RO, Gal AE, Bradley RM, Martensson E, Warshaw AL, Laster L. Enzymatic defect in Fabry's disease. $N$ Engl J Med 1967; 264: 1163-7.

3 Kint JA. Fabry's disease: alpha-galactosidase deficiency. Science 1970; 167:1268-9.

4 Wallace HJ. Anderson-Fabry disease. $\mathrm{Br} J \mathrm{Der}$ matol 1973; 88:1-23.

5 Burda CD, Winder PR. Angiokeratoma corporis diffusum universale (Fabry's disease) in female subjects. Am J Med 1967; 42:293-301.

6 Ruiter M. Angiokeratoma corporis diffusum. Arch Dermatol Syphilol 1953; 68:21-7.

7 Tabira T, Goto I, Kuroiwa Y. Neuropathological and biochemical studies in Fabry's disease. Acta Neuropathol 1974; 30:345-54.

8 Wise D, Wallace HJ, Jellinek EH. Angiokeratoma corporis diffusum. A clinical study of eight affected families. $Q J$ Med 1962;31:177206.

9 Anderson W. A case of angeio-keratoma. $\mathrm{Br} J$ Dermatol 1898; 10:113-7.

10 Steward VW, Hitchcock C. Fabry's disease (Angiokeratoma corporis diffusum). Pathol Eur 1968; 3:377-88.

11 Tulleken CAF. Giant aneurysms of the posterior fossa presenting as space occupying lesions. Clin Neurol Neurosurg 1976; 79:161-87.

12 Stehbens WE. Pathology of the Cerebral Blood Vessels. Saint Louis: CV Mosby, 1972.

13 Colley JR, Miller DL, Hutt MSR, Wallace HJ, De Wardener HE. The renal lesion in angiokeratoma corporis diffusum. $\mathrm{Br} \mathrm{Med} J$ 1958; 1:1266-8.

14 Von Gemmingen G, Kierland RR, Opitz JM. Angiokeratoma corporis diffusum (Fabry's disease). Arch Dermatol 1965; 91:206-18.

15 Velzeboer CMJ, De Groot WP. Ocular manifestations in angiokeratoma corporis diffusum. (Fabry). Br J Ophthamol 1971; 55:683-92.

16 Rahman AN, Lindenberg $R$. The neuropathology of hereditary dystopic lipidosis. Arch Neurol 1963; 9:373-85.

17 Jensen E. On the pathology of angiokeratoma corporis diffusum (Fabry). Acta Pathol Microbiol Scand 1966; 68:313-31.

18 Christensen Lou HO, Reske-Nielsen E. The central nervous system in Fabry's disease. Arch Neurol 1971; 25:351-9.

19 Mitchell PC, Taaffe A. Delayed diagnosis in angiokeratoma corporis diffusum (AndersonFabry's disease). Br Med J 1977; 1:83. 